Article

\title{
Impacts of Re-Vegetation on Surface Soil Moisture over the Chinese Loess Plateau Based on Remote Sensing Datasets
}

\author{
Qiao Jiao ${ }^{1,+}$, Rui Li ${ }^{1,2,3, *}$, Fei Wang ${ }^{1,2,3, *,+}{ }^{\dagger}$, Xingmin $\mathrm{Mu}^{1,2,3}$, Pengfei $\mathrm{Li}^{2}$ and Chunchun An ${ }^{2}$ \\ 1 College of Natural Resources and Environment, Northwest A\&F University, Yangling 712100, China; \\ jiaoqiao_1599@163.com (Q.J.); xmmu@ms.iswc.ac.cn (X.M.) \\ 2 Institute of Soil and Water Conservation, Chinese Academy of Sciences and Ministry of Water Resources, \\ Yangling 712100, China; forest@nwsuaf.edu.cn (P.L.); anchunchun213@163.com (C.A.) \\ 3 Institute of Soil and Water Conservation, Northwest A\&F University, Yangling 712100, China \\ * Correspondence: lirui@ms.iswc.ac.cn (R.L.); wafe@ms.iswc.ac.cn (F.W.); Tel.: +86-29-8701-9829 (R.L. \& F.W.); \\ Fax: +86-29-8701-2210 (R.L. \& F.W.) \\ + These authors contributed equally to this work.
}

Academic Editors: Angela Lausch, Marco Heurich, Nicolas Baghdadi and Prasad S. Thenkabail Received: 4 November 2015; Accepted: 15 February 2016; Published: 19 February 2016

\begin{abstract}
A large-scale re-vegetation supported by the Grain for Green Project (GGP) has greatly changed local eco-hydrological systems, with an impact on soil moisture conditions for the Chinese Loess Plateau. It is important to know how, exactly, re-vegetation influences soil moisture conditions, which not only crucially constrain growth and distribution of vegetation, and hence, further re-vegetation, but also determine the degree of soil desiccation and, thus, erosion risk in the region. In this study, three eco-environmental factors, which are Soil Water Index (SWI), the Normalized Difference Vegetation Index (NDVI), and precipitation, were used to investigate the response of soil moisture in the one-meter layer of top soil to the re-vegetation during the GGP. SWI was estimated based on the backscatter coefficient produced by the European Remote Sensing Satellite (ERS-1/2) and Meteorological Operational satellite program (MetOp), while NDVI was derived from SPOT imageries. Two separate periods, which are 1998-2000 and 2008-2010, were selected to examine the spatiotemporal pattern of the chosen eco-environmental factors. It has been shown that the amount of precipitation in 1998-2000 was close to that of 2008-2010 (the difference being $13.10 \mathrm{~mm}$ ). From 1998-2000 to 2008-2010, the average annual NDVI increased for 80.99\%, while the SWI decreased for $72.64 \%$ of the area on the Loess Plateau. The average NDVI over the Loess Plateau increased rapidly by $17.76 \%$ after the 10-year GGP project. However, the average SWI decreased by $4.37 \%$ for two-thirds of the area. More specifically, $57.65 \%$ of the area on the Loess Plateau experienced an increased NDVI and decreased SWI, $23.34 \%$ of the area had an increased NDVI and SWI. NDVI and SWI decreased simultaneously for $14.99 \%$ of the area, and the decreased NDVI and increased SWI occurred at the same time for $4.02 \%$ of the area. These results indicate that re-vegetation, human activities, and climate change have impacts on soil moisture. However, re-vegetation, which consumes a large quantity of soil water, may be the major factor for soil moisture change in most areas of the Loess Plateau. It is, therefore, suggested that Soil Moisture Content (SMC) should be kept in mind when carrying out re-vegetation in China's arid and semi-arid regions.
\end{abstract}

Keywords: the Loess Plateau; Grain for Green Project (GGP); Soil Water Index (SWI); Normalized Difference Vegetation Index (NDVI); remote sensing; precipitation; China 


\section{Introduction}

Vegetation canopies diminish raindrop energy; stems and litter disperse runoff, reducing runoff and erosion [1]. Root systems improve the resistance of soil to runoff. As a result, re-vegetation is widely applied across the world as one of the most important erosion control measures [2,3].

A widely-renowned ecological rehabilitation program, "Grain for Green Project" (GGP), was initiated by the Chinese government in 1998 to control soil erosion and flashfloods on hill slopes in order to reduce the sedimentation of river beds and to improve the sustainability of the eco-hydrological system on the Loess Plateau [4]. The GGP has shown remarkable success in terms of ecological restoration and agricultural production, through encouraging local farmers to convert cropland on slopes to grassland and forest by providing subsidies in the form of food and money. It has now been operating for more than 10 years, largely improving the natural environment in parts of the Loess Plateau [5]. The physical and chemical characteristics of the soil were improved, while vegetation communities were gradually stabilized [6]. In particular, measures of returning croplands to forest adopted in the GGP have been demonstrated to be effective approaches to soil and water conservation in hilly loess regions [6].

Although remarkable achievements on soil erosion control have been obtained by re-vegetation promoted by the GGP, there are still debates on whether re-vegetation on the Loess Plateau positively or negatively influences SMC conditions. Some authors found that plant canopy shadows reduced land surface temperature and soil evaporation and, thereafter, increased SMC [7]. However, other authors suggested that vegetation cover had negative impacts on SMC. For example, artificial forest land and grassland increase precipitation interception and transpiration. This will increase total water consumption, leading to a negative soil storage balance and, eventually, an enhanced soil desiccation [7-9]. The above contradictory findings demonstrate the requirement of additional knowledge on how exactly re-vegetation influences SMC, given that SMC crucially constrains the growth and distribution of vegetation and the erosion risk. Moreover, it should be noted that these findings were drawn mainly based on traditional experimental methods (e.g., on-site monitoring), which were suitable for the investigation of soil moisture change at small scales (e.g., patch, hillslope scales) rather than large scales (e.g., regional, global scales). However, given the great spatial variability of soil moisture [10], it may be a mistake to apply the findings obtained at small scales elsewhere to eventually achieve conclusions on SMC change and its reactions to vegetation cover change over a large space such as the Loess Plateau. Thus, there was a need to explore the response of the SMC to re-vegetation promoted by the GGP across the whole of the Loess Plateau.

Remotely-sensed datasets are widely acknowledged as a useful product to detect vegetation cover, soil moisture, and their changes over large areas. There have been many algorithms developed for the estimation of vegetation cover change based on remote sensing data [11]. Normalized difference vegetation index (NDVI), which reflects green vegetation photosynthetic activity [12], has been adopted in numerous studies that require the spatial pattern of vegetation and plant phenology over large areas as a useful and reliable monitoring tool for vegetation health and dynamics. Microwave remote sensing technology provides an effective means of detecting soil moisture information in shallow soil layers, and has been widely applied across arid and semi-arid regions [10,13]. Although there are some weaknesses with microwave sensors, such as the coarse temporal resolution and the requirement of complex calibration process and techniques, they offer two major advantages over other methods: (1) long wavelengths (i.e., low frequency) of microwave sensors penetrate deeper into the soil than the sensors using other bands such as visible light, near-infrared, infrared, etc., and are less likely to be affected by cloud cover or daily time-only acquisition conditions; (2) unlike high-frequency-band sensors, which are highly sensitive to vegetation coverage, microwave sensors are less sensitive to vegetation coverage and, therefore, better account for the SMC [14]. Along with the evolvement of the microwave remote sensing technology, there have been a variety of methods developed for the interpretation and utilization of datasets produced by microwave sensors in the past several decades. In this study, the SWI, defined as the percentage of saturation soil moisture to describe the 
average profile SMC between 0 and $1 \mathrm{~m}$ deep, was employed to investigate the regional differences and changes in soil moisture. The SWI was produced with a semi-empirical model established by Wagner et al. $[15,16]$ based on surface soil moisture measurements retrieved from back-scatterometer coefficients of the Europe Remote Sensing Satellite (ERS-1/2) and Meteorological Operational Satellite Program (MetOp).

This paper aims to understand the impact of large-scale re-vegetation during the GGP on soil moisture condition based on NDVI and SWI datasets. We firstly examined the spatial pattern of SMC and corresponding vegetation coverage and precipitation over two chosen periods since the beginning of GGP (i.e., 1998-2000 and 2008-2010), and then investigated the relationship between changes in soil moisture, vegetation coverage and precipitation.

\section{Materials and Methods}

\subsection{Study Site}

The Loess Plateau lies in the upper and middle reaches of the Yellow River, China, covering an area of approximately $624,000 \mathrm{~km}^{2}$ (Figure 1). It adjoins the Taihang Mountains in the east, the Riyue Mountains in the west, the Qinling Mountains in the south, and the Yin Mountains in the north (from $100^{\circ} 54^{\prime} \mathrm{E}$ to $114^{\circ} 33^{\prime} \mathrm{E}$ and $33^{\circ} 43^{\prime} \mathrm{N}$ to $41^{\circ} 16^{\prime} \mathrm{N}$ ) [8]. The name of the plateau refers to the main loess material: the silty sediment that has been deposited by windstorms on the plateau over time. Loess is a highly erosion-prone soil that is susceptible to the forces of wind and water; in fact, the soil of this region has been called the "most highly erodible soil on the earth" [17]. The Loess Plateau, including arid, semi-arid, and semi-humid regions, is categorized into the continental climate zone of the middle latitudes (Koeppen's BSK climate type) according to the Köppen-Geiger climate classification [18]. The dominant vegetation cover is grasslands. Average annual precipitation is approximately $400 \mathrm{~mm}$, ranging between less than $200 \mathrm{~mm}$ in the northwest and more than $600 \mathrm{~mm}$ in the southeast. The seasonal distribution of the precipitation is very uneven due to the influence of the monsoon season [18], and precipitation is restricted mostly in June to September and mainly in the form of intensive storms on approximately $69.33 \%$ of the area. The average annual actual evaporation is spatially highly variable, and ranges from 820 to $1650 \mathrm{~mm}$, which is much higher than the amount of precipitation [19]. The landscape is dominated by low terrain in the southeast and high terrain in the northwest of the Loess Plateau, thus forming a complex geomorphology. The main soil types are cinnamon soil, dark loessal soil, and loessal soil. Although the deep and loose loess soil is capable of storing a large amount of water, large porosity of the soil leads to a fast evaporation and poor water retention. Coupled with serious soil erosion, these characteristics induce a low SMC, severe soil drought, vulnerability, and deterioration of the ecological environment [19].

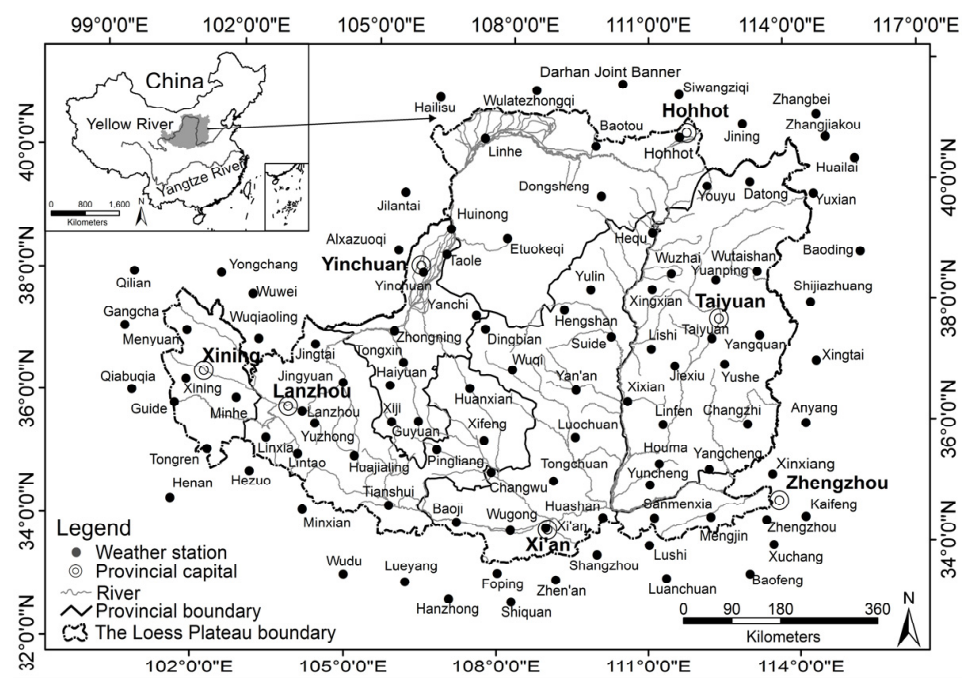

Figure 1. Location of the study site and distribution of weather stations. 


\subsection{Data Collection}

On the Loess Plateau, precipitation is the dominant influencing factor of SMC given the underground water is too deep to recharge the SMC. So, the impact of precipitation needed to be weakened as far as possible in order to detect the impact of re-vegetation on SMC since the beginning of the GGP (1998). Based on an analysis of continuous time-series of precipitation between 1998 and 2010, mean annual precipitation of the Loess Plateau for 1998-2000 (the beginning of the GGP) and 2008-2010 (ten years after the beginning of the GGP) were close to one another (the difference being $13.10 \mathrm{~mm}$ ). As such, changes in SMC between these two periods resulting from precipitation were relatively weak so that the influence of vegetation cover change can be detected. Therefore, we chose 1998-2000 and 2008-2010 for analysis in the study. SWI, NDVI, and precipitation were employed to investigate the spatial pattern of soil moisture changes between the two periods and how these changes were affected by vegetation restoration and precipitation variation.

\subsubsection{SWI Data}

The SWI data were extracted from the Essential Climate Variable Soil Moisture (ECV SM) dataset, which consisted of the "Active Product", "Passive Product", and "Combined Product". The data employed in the study were the "Active Product", which is a consistent dataset produced based on the outputs of ERS-1/2 scatterometer [15] and its directly applicable successor Advanced Scatterometer (ASCAT) in terms of the method [20]. The ERS scatterometer has been flown on board the ERS-1 (1991-1996) and ERS-2 (1995-present). The SWI datasets were not available between 2001 and 2003 [21]. The ERS scatterometer operates in the $\mathrm{C}$ band $(5.3 \mathrm{GHz})$ with vertical polarization. The spatial resolution of the ERS scatterometer soil moisture data was $50 \mathrm{~km}$, and the temporal resolution was approximately 10 days [22]. Compared to ERS scatterometer, ASCAT, loaded on MetOp, offers a multiple viewing direction capability, which better accounts for the effects of vegetation and surface roughness. ASCAT is also an active microwave and vertically polarized radar. The spatial resolution of ASCAT soil moisture data was $25 \mathrm{~km}$, and temporal resolution was less than three days [15,16].

The surface soil moisture data, representing the SMC in $0-5 \mathrm{~cm}$ soil layer, was retrieved from the radar back-scatterometer coefficient, produced by ERS scatterometers and ASCAT, using a change detection algorithm [15]. This method was developed for the retrieval of the soil moisture datasets from ERS-1/2 by Vienna University of Technology (TU-Wien), and was applied to ASCAT after adaptations $[16,23,24]$. The SWI was derived from the surface soil moisture data using a two-layer water model, representing the soil moisture content in the 1-meter layer of top soil $[15,16]$. SWI was produced as the percentage of saturation soil moisture at a spatial resolution of $0.25^{\circ}$ and a temporal resolution of one day, covering the period of 1992-2010.

The "Active Product" datasets were adopted in this study because, in the datasets, the effects of vegetation on soil moisture have been eliminated [24,25]. SWI is influenced by vegetation and soil surface roughness and the change detection algorithm developed by TU-Wien has been applied to eliminate these effects $[22,24,25]$. Once the effect of vegetation growth and senescence is known for the reference incidence angle, its contribution can be eliminated from the sensitivity of backscattering coefficient at the reference incidence angle of $40^{\circ}$, which equals the difference between backscattering coefficient of a dry and wet soil surface at the so-called "cross-over" angles, where cross-over angle depend on dry and wet soil conditions, respectively [26,27].

The SWI has previously been validated with field soil moisture measurements from China and particularly those from the Loess Plateau. Scipal [22] validated the SWI across the whole of China based on 20967 samples collected at 153 agrometeorological stations. It demonstrated that SWI was capable of reflecting the change of observed soil moisture, with the correlation coefficient between SWI and in-situ soil moisture measurements being 0.55. Zhao et al. [28] found that in China SWI was a good indicator for water availability on local (correlation coefficients between area-averaged SWI and precipitation and in situ soil moisture at $0-10 \mathrm{~cm}$ soil layer were 0.479 and 0.453 ) and regional (correlation coefficient between area-averaged SWI and precipitation was 0.539) scales (all the results have reached the 
0.01 level). For the Loess Plateau, Jiang et al. [29] found that the correlation between the SWI product and precipitation (soil texture) varied in the range of $0.513-0.765(0.751-0.802)(p<0.01)$. Jiao et al. [30] concluded that the correlation between the SWI product and in situ soil moisture measurements in $0-10 \mathrm{~cm}$ soil layer varied in the range of $0.48-0.77(p<0.01)$. Overall, results from previous studies strongly suggested that SWI can be used to represent the actual soil moisture condition over the Loess Plateau.

\subsubsection{NDVI Data}

The NDVI time series were produced by the vegetation sensor (SPOT VGT) carried on the SPOT satellite. The SPOT VGT data were ten day maximum value NDVI synthesis products (VGT-S10) with a $1 \mathrm{~km}$ resolution. They were provided by the Cold and Arid Regions Sciences Data Center at Lanzhou (1998-2008) [31] and Vision on technology (Vito) (2008-2010) [32].

\subsubsection{Precipitation Data}

The monthly precipitation data of 101 weather stations within or nearby the Loess Plateau were provided by the China Meteorological Data Sharing Service System [33] (Figure 1). The unit of precipitation is $\mathrm{mm}$.

\subsection{Methods}

\subsubsection{Scale Harmonization}

Precipitation, NDVI, and SWI data were transferred to the same scale. The precipitation was interpolated with the ordinary kriging method developed by Krige [34] to a $25 \mathrm{~km}$ resolution, which matched the SWI grid size. The NDVI data, originally with a $1 \mathrm{~km}$ resolution, were resampled to match the SWI grid $(25 \mathrm{~km})$ with the nearest resampling method, which performed a nearest neighbor assignment.

\subsubsection{Spatial and Temporal Characteristics of Seasonal and Annual Precipitation, NDVI, and SWI}

Seasons were defined according to the international standard of season division, in which spring is March-May, summer is June-August, autumn is September-November, and winter is December-February. Seasonal and annual precipitation was summed from monthly values. Seasonal and annual SWI were averaged from monthly values. The change detection method that was used to calculate the SWI data requires that the ground not be frozen or covered with wet snow [26]. Therefore, winter was not considered in the study. The maximum value composite (MVC) methods were used to derive the annual, seasonal, and monthly NDVI [35]. The spatial pattern of changes in seasonal and annual precipitation, SWI, and NDVI between 1998-2000 and 2008-2010 was investigated after the scale harmonization procedure as described in Section 2.3.1. The temporal characteristics of the seasonal precipitation, SWI, and NDVI were also investigated in terms of maximum, minimum, mean $(\mu)$, and standard deviation (s) with the spatial analyst tools of ArcGIS 10.0. The Coefficient of Variation $(\mathrm{CV})$ of seasonal SWI, NDVI, and precipitation, was given by:

$$
\mathrm{CV}=\mathrm{s} / \mu \times 100 \%
$$

\subsubsection{Cross-Checking of Changes in Mean Annual SWI, NDVI, and Precipitation}

A cross-checking of changes in mean annual SWI, NDVI, and precipitation during the period of 1998-2000 and 2008-2010 was conducted. Changes in mean annual SWI, NDVI, and precipitation were firstly reclassified, and then an overlay analysis among the reclassified layers was implemented via the spatial analyst tools of ArcGIS 10.0 to detect the relationship between soil moisture and vegetation coverage and precipitation. 


\section{Results}

\subsection{Precipitation Change}

Total annual precipitation in 2008-2010 was $400.97 \mathrm{~mm}$, which was slightly higher (1.66\%) than in 1998-2000 (387.87 mm). Precipitation peaked in summer and bottomed in spring. The spring, summer, and autumn precipitation of 1998-2000 had a larger CV than that of 2008-2010, indicating that the temporal pattern of precipitation in 1998-2000 was more unevenly distributed than that of 2008-2010 (Table 1).

Table 1. Statistical characteristics of seasonal precipitation on the Loess Plateau.

\begin{tabular}{ccccccc}
\hline \multirow{2}{*}{ Season } & \multirow{2}{*}{ Period } & \multicolumn{3}{c}{ Precipitation (mm) } & \multirow{2}{*}{ STD } & \multirow{2}{*}{$\begin{array}{c}\text { Coefficient } \\
\text { Variation (\%) }\end{array}$} \\
\cline { 2 - 5 } & & Minimum & Maximum & Mean & & 41.97 \\
\multirow{2}{*}{ Spring } & 1 & 25.96 & 189.15 & 86.63 & 36.36 & 37.92 \\
\hline \multirow{2}{*}{ Summer } & 2 & 22.95 & 177.89 & 77.88 & 29.53 & 32.06 \\
& 1 & 66.87 & 420.32 & 219.92 & 70.51 & 31.89 \\
\hline \multirow{2}{*}{ Autumn } & 1 & 76.65 & 414.59 & 217.18 & 69.25 & 38.37 \\
& 2 & 18.89 & 191.69 & 81.32 & 31.20 & 26.90 \\
\hline
\end{tabular}

Note: Period 1: 1998-2000; Period 2: 2008-2010.

Annual precipitation change from 1998-2000 to 2008-2010 shows opposite trends in northern and southern parts of the Loess Plateau, being positive in the north and negative in the southeast and southwest (Figure 2a). More specifically, there was more precipitation in the north of Yinchuan City, Wuqi County, and Taiyuan City. Peaking around Yulin City, the average annual precipitation in 2008-2010 was $100 \mathrm{~mm}$ greater than that in 1998-2000. In the south region of Yinchuan City, Wuqi County, and Taiyuan City, the average annual precipitation decreased by more than $100 \mathrm{~mm}$ in 2008-2010 at two locations: west of Zhengzhou City, and the periphery of Lanzhou City.

The spatial pattern of the difference in seasonal precipitation during the two chosen periods were remarkable (Figure $2 b-d$ ). In spring, there was $67.03 \%$ of area with decreased precipitation, leading to droughts and thereafter soil moisture deficiency in the region, especially in the south of the Loess Plateau. In summer, precipitation increased in 54.98\% of the area located in the northern, central, and southern parts of the Loess Plateau. There was about $94.22 \%$ of the area with precipitation increasing in autumn.

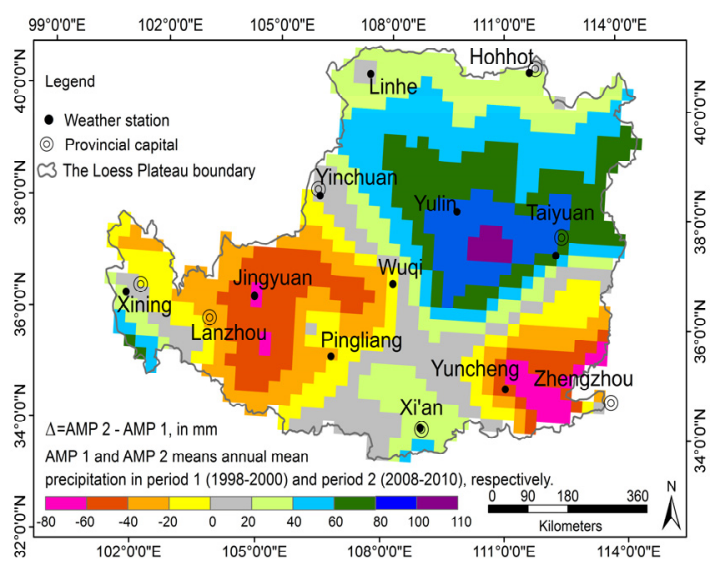

(a)

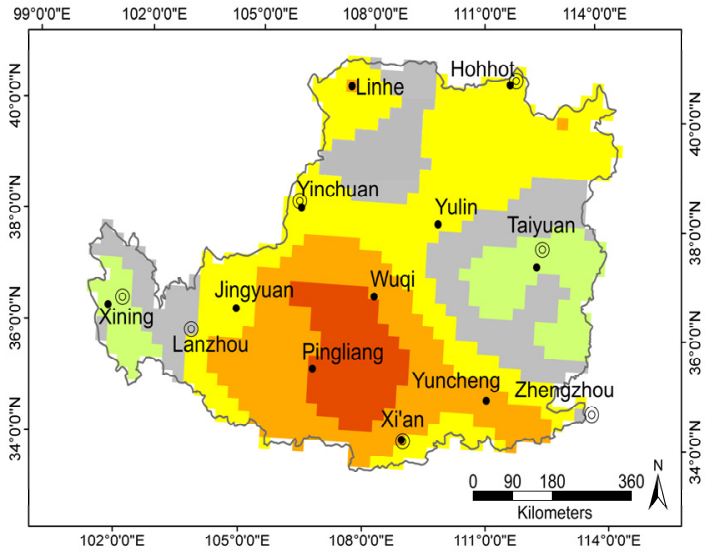

(b)

Figure 2. Cont. 


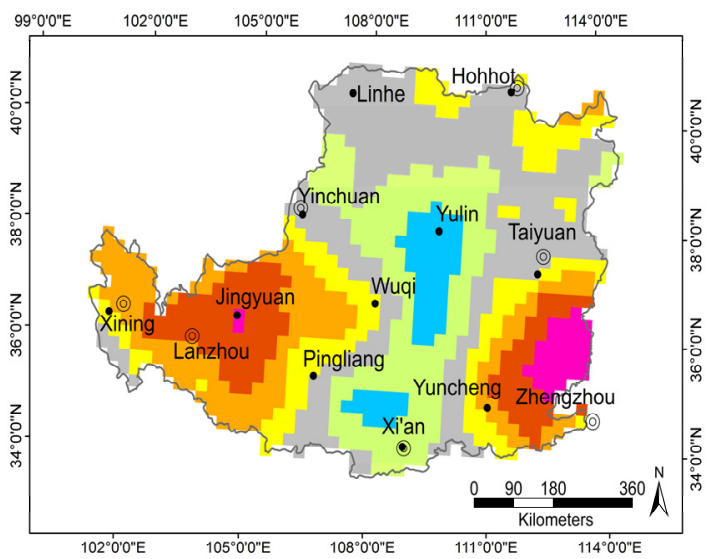

(c)

Legend $(\Delta=$ prep.2 - prep.1, in mm)
$(-80.0,-60.0)$
$[-60.0,-40.0)$
$\square[-40.0,-20.0)$
$\square[20.0,40.0)$
$\square[40.0,60.0)$

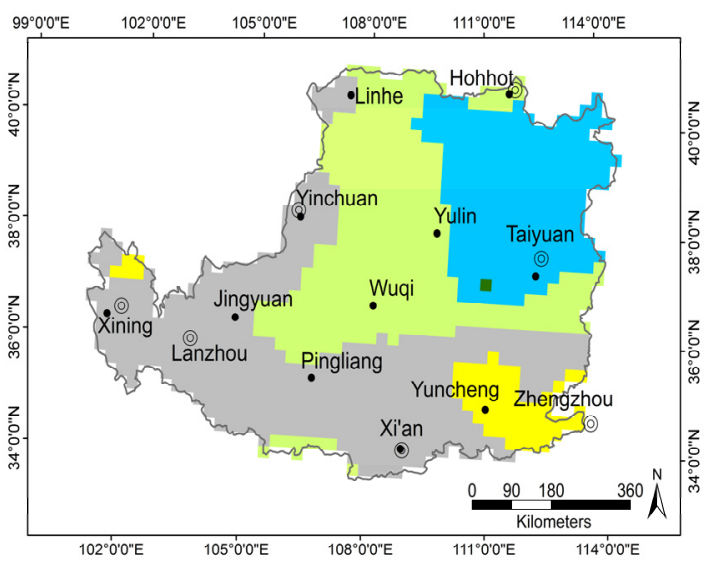

(d)

- Weather station (?) Provincial capital @ $\backsim$ The Loess Plateau boundary

prep. 1 and prep. 2 means the precipitation in period 1 (1998-2000)

and period 2 (2008-2010), respectively.

Figure 2. The spatial differences of mean annual precipitation (a); the precipitation for the three seasons (spring (b); summer (c) autumn (d)) between the two periods on the Loess Plateau.

\subsection{NDVI Change}

NDVI increased greatly on the Loess Plateau from 1998-2000 and 2008-2010 (Table 2). The CV of NDVI showed a large difference in spring, indicating the quick growth of crops at the beginning of growing season. The CV became stable in summer and autumn, and was slightly higher in autumn than in summer, indicating that the growing season ended.

Compared with 1998-2000, more than $80.99 \%$ of the Loess Plateau had a distinctly increased NDVI in 2008-2010 (Figure 3a) except some small patches and areas in the north of Lanzhou City, the north of Yinchuan City, the south of Xining, and periphery of Xi'an City. In spring, the area with increased NDVI accounted for $77.46 \%$ of the Loess Plateau (Figure $3 b$ ). In summer, the regions with increased NDVI accounted for $88.63 \%$ of the area (Figure 3c). Autumn NDVI increased significantly for approximately $93.76 \%$ of the Loess Plateau over the 10 years (Figure $3 \mathrm{~d}$ ).

Table 2. Statistical characteristics of seasonal NDVI on the Loess Plateau.

\begin{tabular}{ccccccc}
\hline \multirow{2}{*}{ Season } & Period & \multicolumn{3}{c}{ NDVI } & STD & $\begin{array}{c}\text { Coefficient } \\
\text { Variation (\%) }\end{array}$ \\
\cline { 2 - 5 } & & Minimum & Maximum & Mean & & 0.17 \\
\hline \multirow{2}{*}{ Spring } & 1 & 0.06 & 0.78 & 0.29 & 58.62 \\
& 2 & 0.06 & 0.83 & 0.34 & 0.19 & 55.00 \\
\hline \multirow{2}{*}{ Summer } & 1 & 0.08 & 0.82 & 0.45 & 0.18 & 40.22 \\
& 2 & 0.09 & 0.89 & 0.52 & 0.20 & 37.69 \\
\hline \multirow{2}{*}{ Autumn } & 1 & 0.08 & 0.82 & 0.38 & 0.17 & 43.42 \\
& 2 & 0.09 & 0.84 & 0.47 & 0.18 & 38.51 \\
\hline
\end{tabular}

Note: Period 1: 1998-2000; Period 2: 2008-2010. 


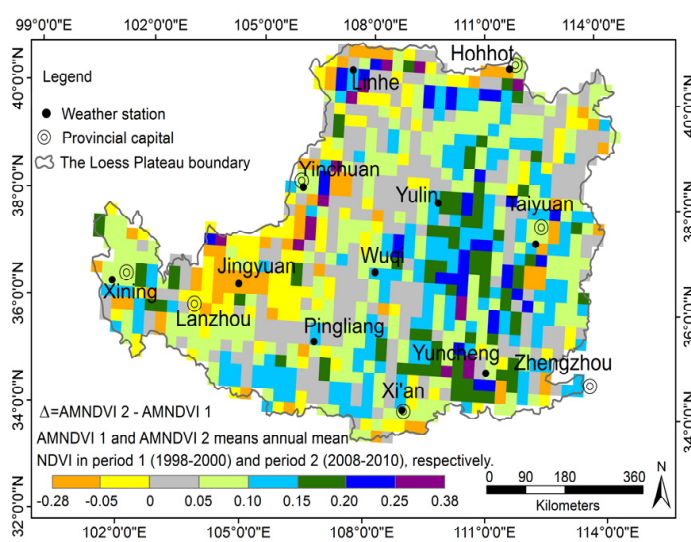

(a)

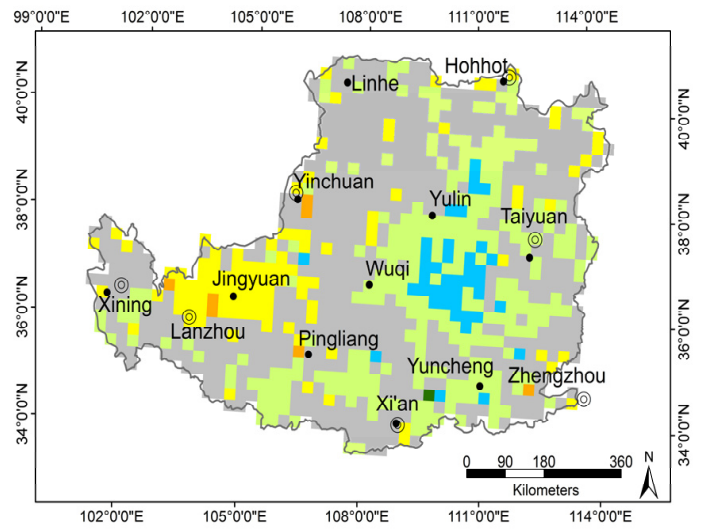

(c)

Legend $(\Delta=$ NDVI 2 - NDVI 1)

$\square(-0.35,-0.20) \square[-0.20,-0.10) \square[-0.10,0) \square[0,0.10)$

$\square[0.10,0.20) \quad \square[0.20,0.30) \quad \square[0.30,0.40) \quad \square[0.40,0.50)$

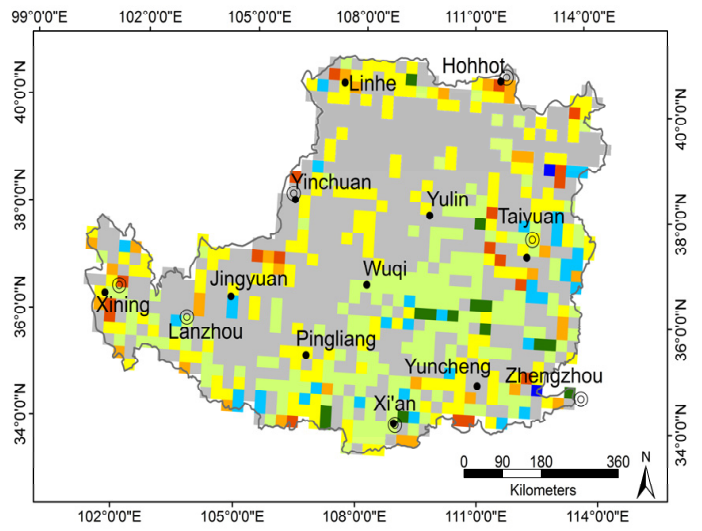

(b)

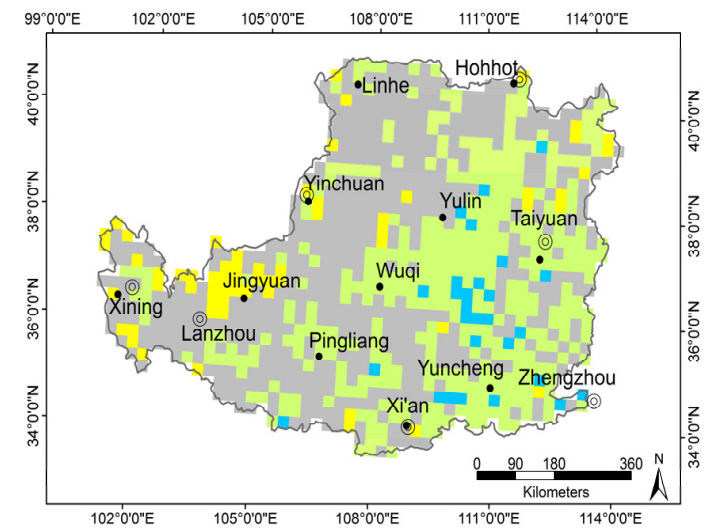

(d)

- Weather station ๑ Provincial capital $\backsim$ The Loess Plateau boundary

NDVI 1 and NDVI 2 means the NDVI in period 1 (1998-2000) and period 2 (2008-2010), respectively.

Figure 3. The spatial differences of mean annual NDVI (a), the NDVI for the three seasons (spring (b); summer (c); and autumn (d)) between the two chosen periods on the Loess Plateau.

\subsection{SWI Change}

Compared to 2008-2010, the mean SWI became lower in 1998-2000 in spring and autumn (Table 3). The seasonal difference of SWI on the Loess Plateau was distinct. Mean SWI was highest in autumn and lowest in spring. Compared to summer and autumn, the CV of spring soil moisture showed a greater variation, indicating that soil moisture was more temporally uneven.

Table 3. Statistical characteristics of seasonal SWI on the Loess Plateau.

\begin{tabular}{ccccccc}
\hline \multirow{2}{*}{ Season } & Period & \multicolumn{3}{c}{ SWI (\%) } & STD & $\begin{array}{c}\text { Coefficient } \\
\text { Variation (\%) }\end{array}$ \\
\cline { 3 - 5 } & & Minimum & Maximum & Mean & & \\
\hline \multirow{2}{*}{ Spring } & 1 & 5.52 & 73.36 & 30.28 & 12.57 & 41.51 \\
& 2 & 5.84 & 63.31 & 30.48 & 11.38 & 37.34 \\
\hline \multirow{2}{*}{ Summer } & 1 & 13.07 & 79.67 & 48.44 & 12.56 & 25.93 \\
& 2 & 10.75 & 82.18 & 42.98 & 13.34 & 31.04 \\
\hline \multirow{2}{*}{ Autumn } & 1 & 13.60 & 80.61 & 49.76 & 13.11 & 26.35 \\
& 2 & 13.66 & 81.83 & 52.72 & 12.38 & 23.48 \\
\hline
\end{tabular}

Note: period 1: 1998-2000; period 2: 2008-2010. 
In 2008-2010, the spatial pattern of annual SWI was apparently decreased from 1998-2000 in the central and, particularly, southern parts (72.64\%) of the Loess Plateau (Figure $4 \mathrm{a}$ ). The rest $27.36 \%$ of the Loess Plateau had a higher SWI in 2008-2010 compared to 1998-2000, mainly located in the north of the Loess Plateau.

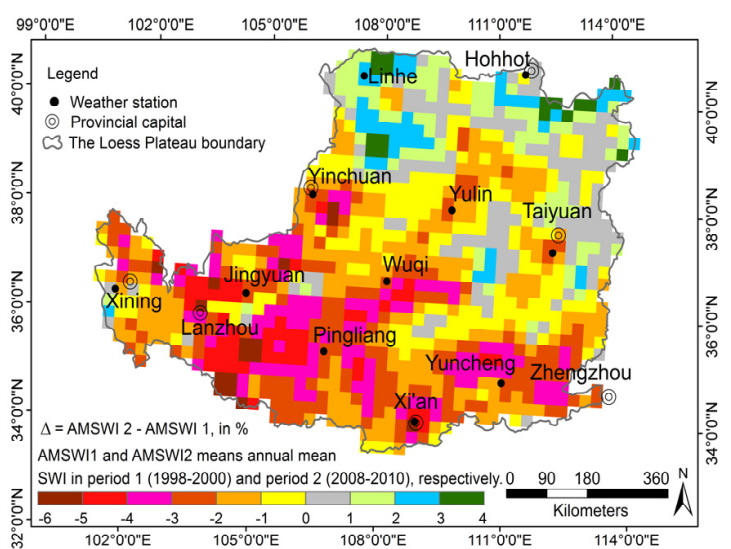

(a)

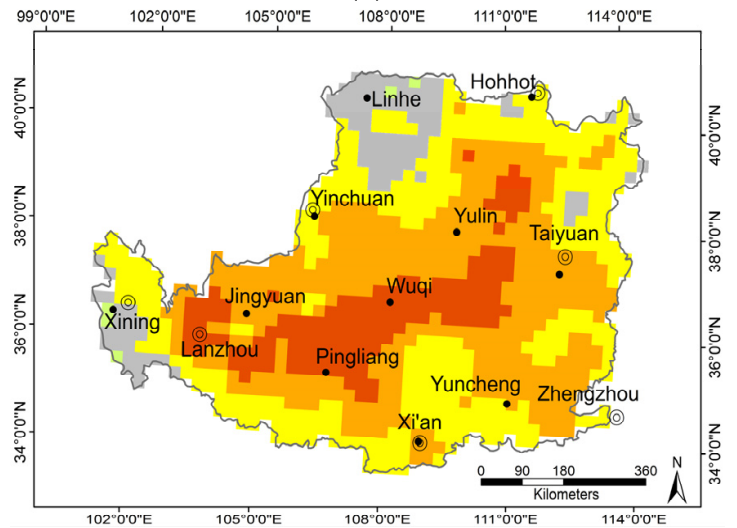

(c)

Legend $(\Delta=$ SWI $2-$ SWI 1 , in $\%)$

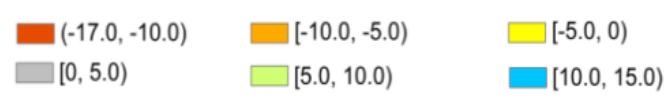

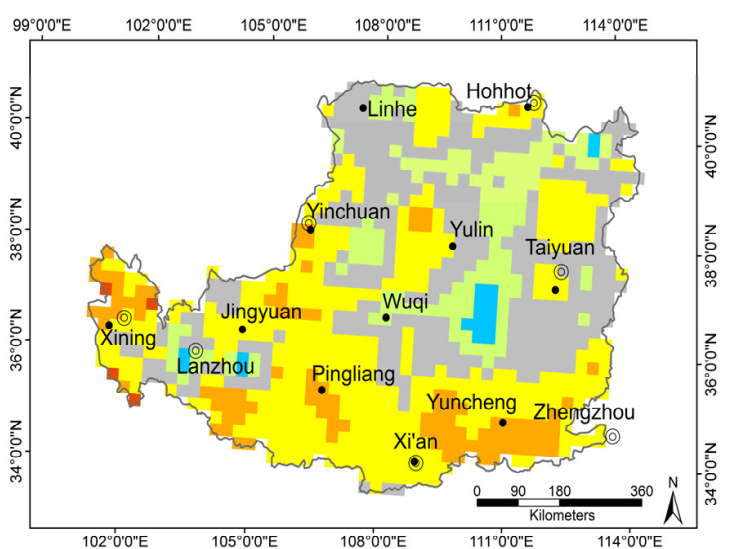

(b)

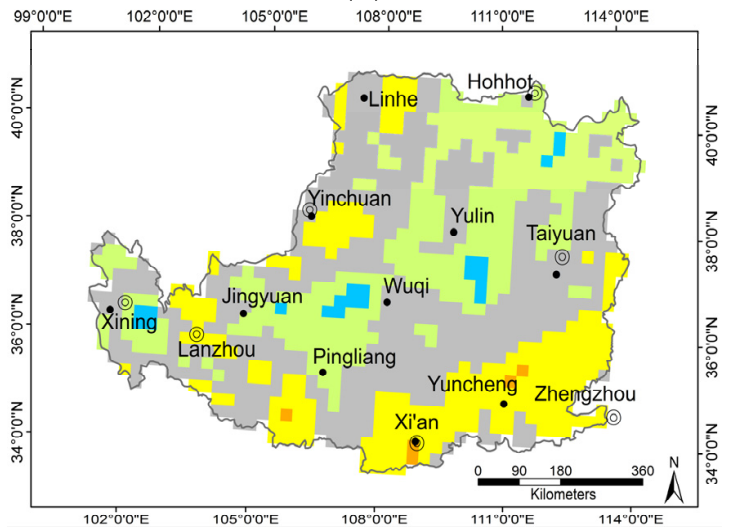

(d)

- Weather station ( Provincial capital $\backsim$ The Loess Plateau boundary

SWI 1 and SWI 2 means the SWI in period 1 (1998-2000)

and period 2 (2008-2010), respectively.

Figure 4. The spatial differences of mean annual SWI (a); the SWI for the three seasons (spring (b); summer (c); and autumn (d)) between 1998-2000 and 2008-2010 on the Loess Plateau.

In spring, the area with increased SWI accounted for $48.39 \%$ of the total area, located in the southwest of the Loess Plateau (Figure $4 \mathrm{~b}$ ). In summer, the areas with negative soil moisture change from 1998-2000 to 2008-2010 occupied 89.94\% of the Loess Plateau (Figure 4c). In autumn, the area of the increased SWI accounted for $76.86 \%$ of the total area (Figure $4 \mathrm{~d}$ ).

\subsection{The Relationship between Changes of NDVI and SWI}

Through intersecting the changes of annual NDVI and annual SWI, we found that areas with increased NDVI and decreased SWI accounted for the largest part of the Loess Plateau (Figures 5 and 6). Overall, vegetation cover increased for about $80.99 \%$, while soil moisture decreased for about 72.64\% of the Loess Plateau. During the period of 1998-2000 and 2008-2010, the increased vegetation cover encountered decreased soil moisture across approximately 57.65\% of the Loess Plateau. Both soil moisture and vegetation coverage increased for $23.34 \%$ of the Loess Plateau, such as northern Shaanxi province, northern Shanxi province, and southwestern Inner Mongolia. Approximately 14.99\% of the 
Loess Plateau witnessed the declined soil moisture and vegetation coverage. The rest of Loess Plateau $(4.02 \%)$ had a decreased vegetation cover and increased SWI.

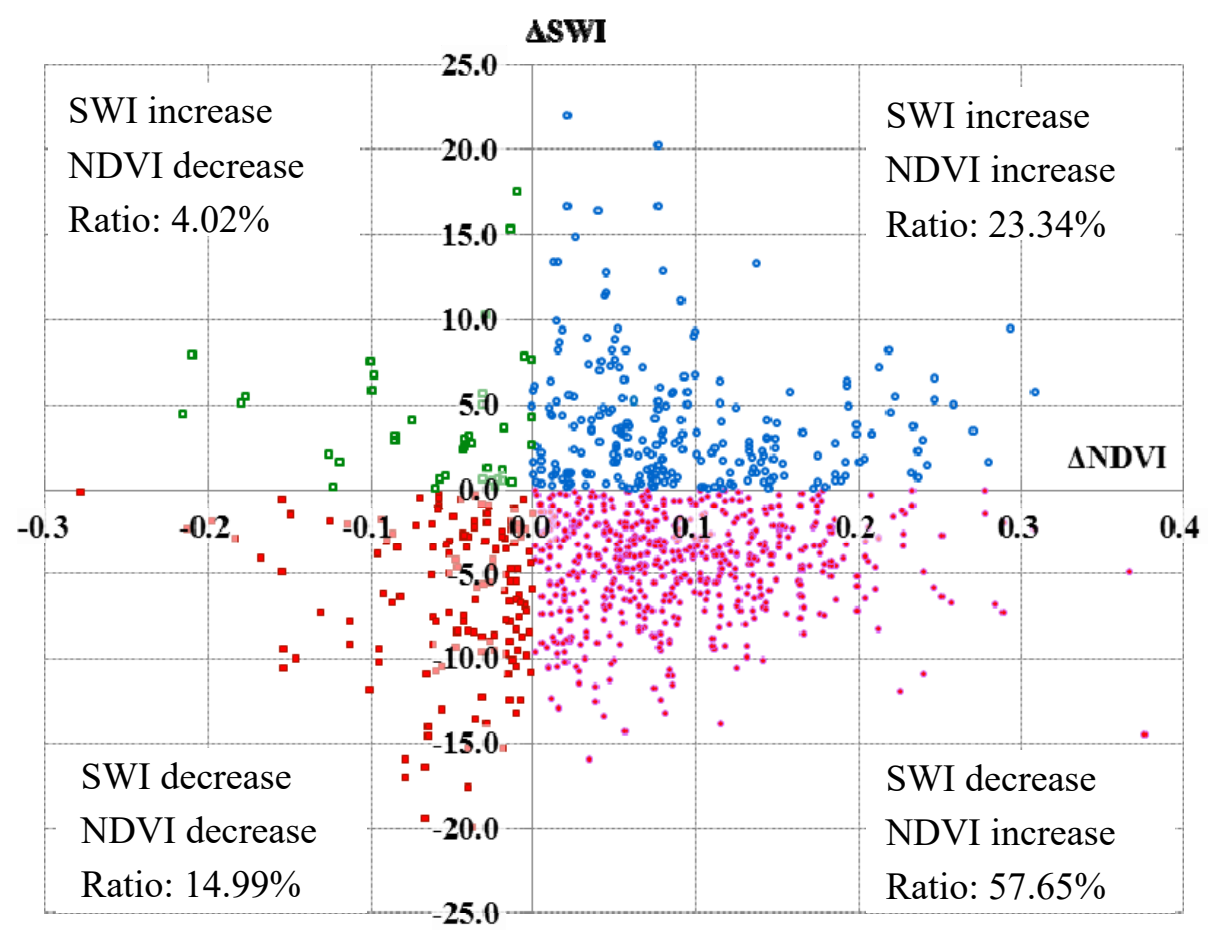

Figure 5. Changes in the SWI and NDVI on the Loess Plateau. $\Delta$ SWI/ $\triangle$ NDVI represents the difference of mean annual SWI/NDVI in 1998-2000 and 2008-2010.

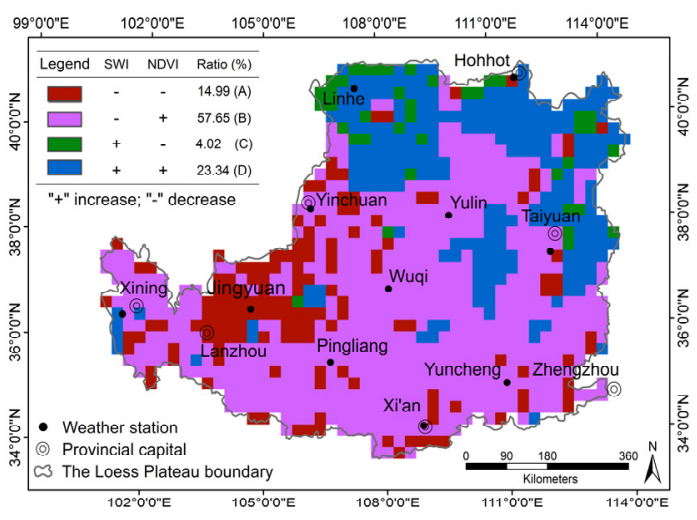

(a)

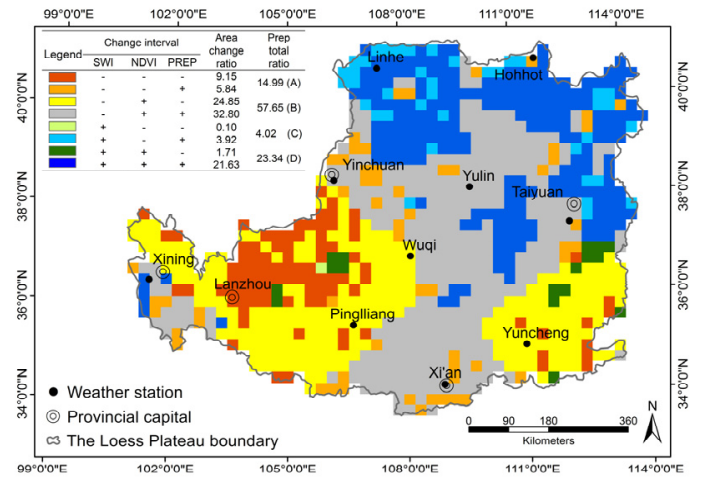

(b)

Figure 6. Spatial distribution of area change in the SWI and NDVI (a); SWI, NDVI, and precipitation (b) on the Loess Plateau.

\subsection{The Relationship among SWI, NDVI, and Precipitation}

For the area with the decreased SWI and increased NDVI, precipitation exhibited both increasing and decreasing trends (Table 4). Areas with increasing precipitation was mainly located in the northern Loess Plateau (Figure $6 \mathrm{~b}$ ), accounting for $32.80 \%$ of the Loess Plateau, while regions subject to the decreasing precipitation occupied $24.85 \%$ of the Loess Plateau, mainly distributed in the southeast and southwest of the Loess Plateau. Another interesting result is in the west of the Loess Plateau; the precipitation, SWI and NDVI decreased simultaneously in the southwest, accounting for $9.15 \%$ of the Loess Plateau, and all three of them increased in the north, accounting for $21.63 \%$ of the Loess Plateau. 
Table 4. The changes of precipitation in the 4 combinations of NDVI-SWI changes.

\begin{tabular}{|c|c|c|c|c|c|c|}
\hline \multirow{2}{*}{-} & \multicolumn{3}{|c|}{ Change Direction } & \multirow{2}{*}{$\begin{array}{c}\text { Area Change } \\
\text { Ratio (\%) }\end{array}$} & \multirow{2}{*}{$\begin{array}{c}\text { Prep Total } \\
\text { Ratio (\%) }\end{array}$} & \multirow{2}{*}{$\begin{array}{c}\text { SWI Change } \\
\text { Ratio (\%) }\end{array}$} \\
\hline & SWI & NDVI & PREP & & & \\
\hline 1 & - & - & - & 9.15 & \multirow{2}{*}{$14.99 \mathrm{~A}$} & -7.94 \\
\hline 2 & - & - & + & 5.84 & & -3.62 \\
\hline 3 & - & + & - & 24.85 & \multirow{2}{*}{$57.65 \mathrm{~B}$} & -5.86 \\
\hline 4 & - & + & + & 32.80 & & -3.43 \\
\hline 5 & + & - & - & 0.10 & \multirow{2}{*}{$4.02 \mathrm{C}$} & 0.13 \\
\hline 6 & + & - & + & 3.92 & & 4.02 \\
\hline 7 & + & + & - & 1.71 & \multirow{2}{*}{$23.34 \mathrm{D}$} & 1.98 \\
\hline 8 & + & + & + & 21.63 & & 3.89 \\
\hline
\end{tabular}

Note: (1) PREP represents precipitation; (2) " -" represent decrease; "+" represent increase; (3) A, B, C and D means the NDVI-SWI intersections (the same as in Figures 5 and 6), respectively.

\section{Discussion}

Soil moisture is a part of hydrological cycle, which is a complex system. There are, therefore, many factors driving changes in soil moisture, such as temperature, precipitation, vegetation, topography, soil texture, etc. In this study, we only explored the relationship among soil moisture, vegetation coverage, and precipitation. Further study is still desirable to examine the effects of other factors on soil moisture.

\subsection{Increased NDVI and Decreased SWI}

It was found that soil moisture decreased and the vegetation increased for about $57.65 \%$ of the Loess Plateau. There was $24.85 \%$ of the area with decreased precipitation, and $32.80 \%$ of the area with increased precipitation. As a result, SWI change ratio was found to be $-5.86 \%$ and $3.43 \%$ for $24.85 \%$ and $32.80 \%$ of the Loess Plateau, respectively (Table 4 ).

For the $24.85 \%$ of the Loess Plateau, the climate became drier from 1998-2000 to 2008-2010. Additionally, fast-growing vegetation consumed large amounts of soil moisture. Soil moisture is not timely supplied by precipitation, this will inevitably enhance the shortage of soil moisture, and sometimes resulted in a dry soil layer up to a depth of $2 \mathrm{~m}$ or more [36,37]. For the $32.80 \%$ of the Loess Plateau, precipitation increased slightly from 1998-2000 to 2008-2010. However, artificial afforestation, which has been demonstrated to consume soil moisture quickly and the amount of soil moisture consumed could be higher than local precipitation [8,9]. This may be the major reason for the decrease of soil moisture in the area under increased precipitation. It is, therefore, implied that vegetation may contribute largely to the decrease of soil moisture on the Loess Plateau. This finding is supported by other studies in arid and semi-arid areas. For example, on the Loess Plateau, Wang (2010) [8] found that increased vegetation cover should decrease surface soil moisture when the precipitation did not change substantially.

If areas covered by the GGP expand, there will be more vegetation planted in the future. The demand of soil moisture will thus be increased, leading to a more serious soil moisture deficit, which possibly constraints the growth and distribution of vegetation and, thus, further re-vegetation in the region. In some cases this has resulted in mortality of the vegetation (e.g., [37,38]), and in other cases while trees survive, their growth is stunted so that some patches of 30 year old plantation trees are only about $20 \%$ of their normal height-colloquially referred to as "little old man trees" [38,39]. It is, therefore, suggested that soil moisture awareness should be kept in mind when carrying out re-vegetation in China's arid and semi-arid regions. 


\subsection{Increased NDVI and SWI}

NDVI and SWI were found to increase at the same time across $23.34 \%$ of the Loess Plateau, which was restricted in the north of the loess plateau. On this area, although the annual precipitation is less than $200 \mathrm{~mm}$, it increased from 1998-2000 to 2008-2010 in the majority of the area. Additionally, the flow of the Yellow River is often used for irrigation of the farmland in the area, recharging the soil moisture to a certain degree. Furthermore, soil moisture increased because the implementation of land reclamation by human activities at the coal mining regions on the Loess Plateau [40]. The above three factors offset the adverse impact of vegetation coverage increase on soil moisture and eventually lead to an improved soil water condition.

\subsection{Decreased NDVI and SWI}

There is about $14.99 \%$ of the Loess Plateau with decreased NDVI and SWI. It had a mean annual precipitation of $240 \mathrm{~mm}$ during the study periods with precipitation on $71.5 \%$ of the area occurring from July to September. The majority of the area was subject to a decreased precipitation from 1998-2000 to 2008-2010. Natural vegetation is sparse and low, vegetation growth is difficult in this dry and vulnerable environment [41]. The area experiences severe drought events frequently, which introduces many problems for local agricultural production. It is, therefore, inferred that the decrease of soil moisture is mainly driven by the drier climate given the low vegetation coverage is unlikely to change the local soil water condition significantly.

\subsection{Decreased NDVI and Increased SWI}

It was also found that the soil moisture increased and the vegetation decreased across about $4.02 \%$ of the Loess Plateau. The majority of the area experienced a wetter climate in 2008-2010 compared to 1998-2000. Therefore, the increased SWI may be due to more precipitation and less water consumption, resulting from increased precipitation and decreased vegetation coverage.

\section{Conclusions}

In this study, the spatiotemporal pattern of SWI, NDVI, precipitation, and their interactions were investigated for the Chinese Loess Plateau between 1998-2000 and 2008-2010 based on the two remote sensing datasets and a measurement dataset. The results showed that average annual NDVI of the Loess Plateau significantly increased across $80.99 \%$ of the area from 1998-2000 to 2008-2010, indicating that vegetation restoration was remarkable after the implementation of the GGP. Precipitation conditions did not change significantly (the difference is $13.10 \mathrm{~mm}$ ). However, SWI, which was retrieved from ECV SM dataset, showed that soil moisture decreased for $72.64 \%$ of the Loess Plateau, demonstrating that soil experienced a tendency of drought in the first ten year of the 21 st Century. Our result demonstrated there was about $57.65 \%$ of the area where the vegetation coverage increased and the surface soil moisture decreased, of which near a half experienced increasing precipitation. There was about $4.02 \%$ of the area which experienced increased soil moisture and decreased vegetation coverage. These findings suggested that vegetation coverage was important for and negatively related to soil moisture variation on the Loess Plateau. There was about $23.34 \%$ of area with the vegetation coverage and surface soil moisture increasing. In this area, human activities, such as land reclamation, largely affected the soil moisture. Therefore, soil water condition was improved during the study period on these areas. The rest $14.99 \%$ showed a decreased trend in the vegetation coverage and soil moisture, which was mainly distributed in the western portion of the Loess Plateau where the mean annual precipitation reduced between 1998-2000 and 2008-2010. Here the drought, which caused vegetation degradation, may be the major driver to encourage soil moisture deficit. The results suggested that excessive reliance on afforestation was risky for the improvement of vegetation coverage in arid and semi-arid regions and we, thus, need to focus on the soil moisture conditions during large scale re-vegetation. 
Acknowledgments: The research was funded by the National Natural Science Foundation of China (41171420), the Key Research Program of the Chinese Academy of Sciences (KZZD-EW-04), the West Light Foundation of The Chinese Academy of Sciences (2013-165-04), the External Cooperation Program of BIC, Chinese Academy of Sciences (16146KYSB20150001), the European Commission Programme Horizon2020 project (635750) and National Key Basic Research Special Foundation of China (2014FY210100).

The authors are grateful to Wolfgang Wagner and Christophe Reimer from Vienna University of Technology, Austria for improving the data quality in our research. We also thank the help of American Journal Experts in language improvement.

Author Contributions: Fei Wang, Qiao Jiao and Rui Li conceived the idea and designed the research framework. Qiao Jiao and Chunchun An carried out data collection and preprocessing. Qiao Jiao and Fei Wang undertook data analysis and manuscript preparation. Xingmin $\mathrm{Mu}$, Rui Li and Pengfei Li contributed to manuscript refinement. All authors contributed to the writing of the manuscript.

Conflicts of Interest: The authors declare no conflict of interest.

\section{References}

1. Li, P. Experimental Studies on the Functional Mechanics of Soil and Water Conservation of Grassland Vegetation in Loess Area. Ph.D. Thesis, Northwest A \& F University, Yangling, China, 1 June 2003. (In Chinese)

2. Evans, M.; Warburton, J. Geomorphology of Upland Peat: Erosion, form and Landscape Change; Blackwell Publishing: Chichester, West Sussex, UK, 2007.

3. Wang, B.; Yang, Q.; Liu, Z.; Meng, Q. Changes of soil erosion intensity due to conversion of farmland to forest and grassland in Yanhe River Basin. Sci. Soil Water Conserv. 2007, 5, 27-33. (In Chinese).

4. Wang, J.; Jiang, Z.; Xia, Z. Grain-for-green policy and its achievements (Chapter 10). In Restoration and Development of the Degraded Loess Plateau, China; Springer: Berlin, Germany, 2014.

5. Mu, L.; Liang, Y.; Han, R. Assessment of the soil organic carbon sink in a project for the conversion of farmland to forestland: A case study in Zichang County, Shaanxi, China. PLOS ONE 2014, 9, e94770. [CrossRef] [PubMed]

6. Yang, G.; Ding, G.; Sun, B.; Zhao, T.; He, K.; He, D. Study on the effects of the project of returning cropland to forest on re-vegetation in loess hilly region-Take Wuqi county in Shaanxi as an example. Res. Soil Water Conserv. 2005, 6, 76-78. (In Chinese)

7. Wang, L.; Wei, S.; Wu, F. Soil water environment and vegetation growth in the hilly and gully region of the Loess Plateau: A case study of Yangou Catchment. Acta Ecol. Sin. 2009, 29, 1543-1553. (In Chinese)

8. Wang, Y. Spatial Distribution and Influence Factors of Dried Soil Layers across the Loess Plateau. Ph.D. Thesis, University of Chinese Academy of Sciences, Yangling, China, 1 November 2010. (In Chinese)

9. Zhang, J.; Li, H.; Xu, J. Soil moisture dynamics of water and soil conservation forest on the Loess Plateau. Acta Ecol. Sin. 2011, 31, 71-81. (In Chinese)

10. Urso, G.; Minacapilli, M. A semi-empirical approach for surfacesoi1 water content estimation from radar data without a-priori information on surface roughness. J. Hydrol. 2006, 321, 297-310. [CrossRef]

11. Luo, Y.; Xu, J.; Yue, W. Research on vegetation indices based on the remote sensing images. Ecol. Sci. 2005, 24, 75-79. (In Chinese)

12. Zribi, M.; Pardé, M.; de Rosnay, P.; Baup, F.; Boulain, N.; Descroix, L.; Pellarin, T.; Mougin, E.; Ottlé, C.; Decharme, B. ERS scatterometer surface soil moisture analysis of two sites in the south and north of the Sahel region of West Africa. J. Hydrol. 2009, 375, 253-261. [CrossRef]

13. Zhou, P.; Ding, J.; Wang, F.; Guljamal, U.; Zhang, Z. Retrieval methods of soil water content in vegetation covering areas based on multi-source remote sensing data. J. Remote Sens. 2010, 14, 959-973.

14. Guo, Y; Shen, J; Zhao, C. Soil moisture monitoring in agricultural lands via active-passive microwave remote sensing. Chin. J. Eco-Agric. 2011, 19, 1162-1167. (In Chinese) [CrossRef]

15. Wagner, W.; Lemoine, G.; Rott, H. A method for estimating soil moisture from ERS scatterometer and soil data. Remote Sens. Environ. 1999, 70, 191-207. [CrossRef]

16. Brocca, L.; Tarpanelli, A.; Moramarco, T.; Melone, F.; Ratto, S.; Cauduro, M.; Ferraris, S.; Berni, N.; Ponziani, F.; Wagner, W.; et al. Soil moisture estimation in alpine catchments through modeling and satellite observations. Vadose Zone J. 2013, 12, 191-207. [CrossRef] 
17. Zhu, X. Soil and Agriculture in Loess Plateau; Agriculture Press: Beijing, China, 1989. (In Chinese)

18. Peel, M.C.; Finlayson, B.L.; McMahon, T.A. Updated world map of the Köppen-Geiger climate classification. Hydrol. Earth Syst. Sci. 2007, 11, 1633-1644. [CrossRef]

19. Yang, W.; Yu, C. Regional Control and Evaluation in the Loess Plateau; Science Press: Beijing, China, 1992. (In Chinese)

20. Scipal, K.; Scheffler, C.; Wagner, W. Soil moisture runoff relation at the catchment scale as observed with coarse resolution microwave remote sensing. Hydrol. Earth Syst. Sci. Discuss. 2005, 2, 417-448. [CrossRef]

21. Parajka, J.; Naeimi, V.; Blöschl, G.; Komma, J. Matching ERS scatterometer based soil moisture patterns with simulations of a conceptual dual layer hydrologic model over Austria. Hydrol. Earth Syst. Sci. 2009, 13, 259-271. [CrossRef]

22. Scipal, K. Global Soil Moisture Retrieval from ERS Scatterometer Data. Ph.D. Thesis, Vienna University of Technology, Wien, Austria, 21 May 2002.

23. Liu, Y.; Parinussa, R.; Dorigo, W.; de Jeu, R.; Wagner, W.; van Dijk, A.; McCabe1, M.; Evans, J. Developing an improved soil moisture dataset by blending passive and active microwave satellite-based retrievals. Hydrol. Earth Syst. Sci. 2011, 15, 425-436. [CrossRef]

24. Wagner, W.; Lemoine, G.; Borgeaud, M.; Rott, H. A study of vegetation cover effects on ERS scatterometer data. IEEE Trans. Geosci. Remote Sens. 1999, 37, 938-948. [CrossRef]

25. Fontaine, B.; Louvet, S.; Roucou, P. Fluctuations in annual cycles and inter-seasonal memory in West Africa: Precipitation, soil moisture and heat fluxes. Theor. Appl. Climatol. 2007, 88, 57-70. [CrossRef]

26. Naeimi, V. Model Improvements and Error Characterization for Global ERS and METOP Scatterometer Soil Moisture Data. Ph.D. Thesis, Vienna University of Technology, Wien, Austria, 5 February 2009.

27. Wagner, W.; Scipal, K.; Pathe, C.; Gerten, D.; Lucht, W.; Rudolf, B. Evaluation of the agreement between the first global remotely sensed soil moisture data with model and precipitation data. J. Geophys. Res. Atoms. 2003, 108. [CrossRef]

28. Zhao, D.; Kuenzer, C.; Fu, C.; Wagner, W. Evaluation of the ERS scatterometer-derived soil water index to monitor water availability and precipitation distribution at three different scales in China. J. Hydrometeorol. 2008, 9, 549-562. [CrossRef]

29. Jiang, C.; Wang, F.; Mu, X.; Li, R. Evaluation of the soil water index and surface soil moisture on the Loess Plateau. J. Irrig. Drain. 2012, 31, 31-36.

30. Jiao, Q.; Wang, F.; Li, R.; Zhang, W. Application of inversion of European Remote Sensing satellites data to investigation of near-surface soil moisture in Loess Plateau. Acta Pedol. Sin. 2014, 51, 1388-1397.

31. Cold and Arid Regions Sciences Data Center. Available online: http://westdc.westgis.ac.cn/data/fecdec7177d1-43c2-b472-8b1c729874cb (accessed on 10 May 2011).

32. Vision on Technology (Vito). Available online: http://www.vito-eodata.be/PDF/portal/Application.html\# Home (accessed on 30 March 2013).

33. China Meteorological Data Sharing Service System. Available online: http://cdc.nmic.cn/home.do (accessed on 13 May 2011).

34. Oliver, M.A.; Webster, R. Kriging: A method of interpolation for geographical information systems. Int. J. Geogr. Inf. Syst. 1990, 4, 313-332. [CrossRef]

35. Holben, B. Characteristics of maximum-value composite images from temporal AVHRR data. Int. J. Remote Sens. 1986, 7, 1417-1434. [CrossRef]

36. Liu, Q.; Yang, Z.; Cui, B. Spatial and temporal variability of annual precipitation during 1961-2006 in Yellow River Basin, China. J. Hydrol. 2008, 361, 330-338. [CrossRef]

37. Wang, L.; Shao, M.; Wang, Q.; Jia, Z.; Li, J. Review of research on soil desiccation in the Loess Plateau. Trans. Chin. Soc. Agric. Eng. 2004, 20, 27-31. (In Chinese).

38. Yang, R.; Fu, B.; Liu, G.; Ma, K. Research on the relationship between water and eco-environment construction in Loess Hilly and Gully Region. Environ. Sci. 2004, 25, 37-42. (In Chinese)

39. Yang, W. Soil water resources and afforestation in Loess Plateau. J. Nat. Resour. 2001, 16, 433-438. (In Chinese) 
40. Li, P. Study on Effects of Vegetation Restoration on Soil Properties and Qualities in Heidaigou Mine Dump. Master Thesis, Northwest A\&F University, Yangling, China, 1 May 2014. (In Chinese)

41. Sun, W.; Song, X.; Mu, X.; Gao, P.; Wang, F.; Zhao, G. Spatiotemporal vegetation cover variations associated with climate change and ecological restoration in the Loess Plateau. Agric. For. Meteorol. 2015, 209-210, 87-99. [CrossRef]

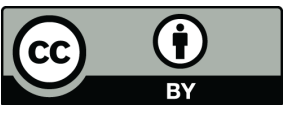

(C) 2016 by the authors; licensee MDPI, Basel, Switzerland. This article is an open access article distributed under the terms and conditions of the Creative Commons by Attribution (CC-BY) license (http://creativecommons.org/licenses/by/4.0/). 